\title{
Training in manual material handling: what is going on in the field?
}

\author{
Veerle Hermans ${ }^{\mathrm{a}, \mathrm{b}^{*}}$, Griet De Preter ${ }^{\mathrm{c}}$, Tine Verschueren ${ }^{\mathrm{d}}$ \\ ${ }^{a}$ Department of Ergonomics, IDEWE, External Prevention Service for Health and Safety at Work, Interleuvenlaan \\ 58, B-3001 Heverlee, Belgium \\ ${ }^{\mathrm{b}}$ Department of Work Psychology, Vrije Universiteit Brussel, Pleinlaan 2, B-1050 Brussels, Belgium \\ ${ }^{\mathrm{c}}$ Flemish Government, Prevention Department, Boudewijnlaan 30 (b44), B-1000 Brussels, Belgium \\ ${ }^{\mathrm{d} A Z}$ Monica, Florent Pauwelslei 1, B-2100 Deurne, Belgium
}

\begin{abstract}
During the last five years, several research review studies have revealed insufficient or even no proof that courses in manual material handling (MMH) are effective at preventing musculoskeletal disorders (MSD). These revelations are placing the current daily practice of MMH trainers under scrutiny. This study analyses how the MMH courses are organised in practice. A web-based questionnaire was developed for trainers. Only trainers giving MMH courses on a regular basis were included. The questionnaire focussed on general characteristics of the courses, content issues and organisational aspects. The results clearly indicated that the MMH courses can only be considered as a means of making employees aware of good manual handling. Not all content issues that should be addressed in effective MMH courses, are looked at in practice. This is mainly due to time restrictions that trainers experience, often imposed by the company. In conclusion, these organisational restrictions might explain the ineffectiveness of the MMH courses and should therefore be resolved.
\end{abstract}

Keywords: manual material handling, training, techniques

\section{Introduction}

Employee training in the principles of occupational health and safety is very popular. Some positive triggers are as follows: educational principles can be used, group teaching is possible (and thus cost-efficient), there is no need for complicated technology and in general people like it [11]. Companies often organise courses in manual material handling $(\mathrm{MMH})$. The aim is not only to increase the knowledge regarding the relationship between postures and physical load, but also to prevent the development of low back pain in the future.

However, several reviews mention the proven ineffectiveness of $\mathrm{MMH}$ courses as a preventive measure for the development of musculoskeletal disorders (MSD) $[2,6,12,16]$. The findings therefore challenge the current widespread practice of advising workers on correct lifting technique. It should be mentioned, that the results of these reviews must be interpreted with caution, because there are often a limited number of studies on the outcomes. Furthermore, in these review studies, the actual content of the specific course is often not investigated, giving rise to a heterogeneity regarding outcomes and study design. In traditional courses, most of the advice and instruction given is about working methods or lifting techniques, although there is some debate about what correct MMH techniques are [6]. The standard techniques are often learned in a classical setting, where the participants learn to lift a standard box. In practice, loads can vary considerably in weight, form, grip, and consequently there is only a limited transfer of learning when only standard conditions are applied. This necessitates a flexible approach towards diverse situations. Burke et al. [5] mentioned that active intervention results in increasing the application of the knowledge regarding $\mathrm{MMH}$ and decreasing the number of accidents and disorders. An active dialogue

${ }^{*}$ Corresponding author. E-mail: veerle.hermans@idewe.be 
between educator and participant is necessary, during which the participant reflects on his own working methods and consequently relates actions and consequences.

Another intervention that shows promising results regarding effectiveness is the inclusion of exercise training. The definition of training can vary considerably in literature, ranging from increasing general physical fitness (cardiovascular training), performing power exercises for trunk muscles, performing stretching exercises and relaxation movements [2]. As far back as 1994, an extensive review [10] mentioned the evidence - although limited at that time based on randomised trials and epidemiological studies that exercises to strengthen back or abdominal muscles and to improve overall fitness can decrease the incidence and duration of low back pain episodes. Since then, other studies have also focused on one or more specific training aspects. For example, strong evidence was found of the positive effect of a worksite physical activity programme on general physical activity and musculoskeletal disorders [13]. Others [3] also mentioned successful physical-activity interventions, especially for specific resistance training that seemed to be superior to all-round physical exercises regarding primary prevention, although for the neck/shoulder region. Nevertheless, all-round physical exercises should also be included, since they could influence overweight and obesity, two factors that have the strongest association with seeking care for low back pain [15]. Furthermore, exercising also stimulates general mood and self-confidence [11,2]. Therefore, exercise programs would have the best result, when combined with other interventions such as functional movements, relaxation, coping strategies and cognitive behaviour interventions [1].

In reality, the current practice regarding $\mathrm{MMH}$ courses will be largely influenced by legislation. According to the Belgian Royal Decree of manual handling (12/08/1993, based on the European guidelines of 1989), employees opposed to the risk of manual handling should be informed about these risks. They should be trained regarding:

- correct manual handling.

- risks related to technical incorrect handling.

- risks related to physical condition, wrong equipment and insufficient knowledge.

Apart from these points, there is no further explicit information regarding the content and organisation of $\mathrm{MMH}$ training.
Therefore, this project was set up to analyse how the $\mathrm{MMH}$ courses are organised in practice, after almost 20 years of legislation. It is investigated if all content issues that should be addressed in effective $\mathrm{MMH}$ courses are looked at in practice.

\section{Methodology}

\subsection{Target group}

A questionnaire was developed for $\mathrm{MMH}$ trainers, contacted via the Belgian Ergonomics Society (BES). Only trainers giving $\mathrm{MMH}$ courses on a regular basis were included. It was explained that the study was focussing on courses organised for a specific group of people of a specific company. The courses are considered as primary prevention courses, not reintegration courses or physical therapy-oriented courses. Courses regarding transfer of patients were also excluded, due to their specific approach.

\subsection{Questionnaire}

A web-based questionnaire was developed, based on the findings in literature regarding the effectiveness of $\mathrm{MMH}$ training. The questionnaire included 5 parts:

- general characteristics regarding $\mathrm{MMH}$ : frequency, duration, location and number of participants.

- content: anatomy, biomechanics, task-related risk factors, practice of MMH techniques, physical exercises.

- work and organisational characteristics: available information before the training, company visit, involvement of supervisor/management.

- follow-up of the course.

- additional remarks of the trainer.

\section{Results and discussion}

35 trainers participated in the study. The results of their questionnaires are summarised in table 1.

In almost $60 \%$ of all $\mathrm{MMH}$ courses, the duration was half a day. For $20 \%$ of the courses, it was even less then 3 hours. In literature, there is no information regarding optimal duration of a course, however it is clear that 4 hours or less is insufficient to incorporate all necessary items. The number of participants per course (on average 13), is slightly larger than Hall [8], 
who recommends groups of 8 to 12 persons. In larger groups, the communication between subjects is too complex and participation and motivation decreases.

The courses focus on the classic approach: anatomy, MMH techniques and job risks are mentioned. As stated in the introduction, the incorporation of physical exercises is an effective strategy for prevention of disorders [6]. However, only half of the trainers provide exercises and emphasis is on power exercises for trunk and leg muscles. Endurance is not often addressed. Stretching exercises and relaxation are introduced by $2 / 3^{\text {rd }}$ of the trainers. The most important reasons for insufficient attention, according to the trainers, are the limited duration and the larger groups, which make organisation of exercises in a classical room difficult. Furthermore, individual coaching is necessary on the correct execution of exercises, motivation and possible health issues.

Table 1

General characteristics regarding MMH courses in Belgium.

\begin{tabular}{|l|l|}
\hline Characteristics of an MMH training course & ( $\%$ of the trainers responding) \\
\hline Number of participants & $7-20$ (average: 13$)$ \\
\hline Duration & $58 \%$ between 3 and 4 hours, $20 \%$ less then 3 hours \\
& $13 \%$ follow-up \\
\hline Location & $49 \%$ in the company with workplace practice \\
\hline \multirow{2}{*}{ Content } & $100 \%$ anatomy \\
& $100 \%$ physical risk factors \\
& $94 \%$ individual risk factors \\
& $30 \%$ psychosocial risk factors \\
& $48 \%$ vibrations \\
& $84 \%$ practice in MMH techniques \\
& $55 \%$ push and pull techniques \\
& $52 \%$ carrying techniques \\
& $32 \%$ no physical exercises \\
& $42 \%$ behavioural change \\
\hline \multirow{2}{*}{ Available information } & $67 \%$ job content \\
& $43 \%$ physical risk factors \\
& $40 \%$ lay-out workplace \\
& $35 \%$ visit to the workplace \\
\hline
\end{tabular}

Many trainers incorporate one aspect of behavioural change, although only $42 \%$ incorporate the three elements (attitudes, social pressure, riskcalculation). For obtaining effective behavioural change, it is important to discuss the individual work situation. $67 \%$ of the trainers have an idea of the job content of the workers and consequently discuss specific problems. However, only $35 \%$ make a preliminary visit to the workplace during which they can observe the working situation of the workers, collect material to include in the course itself, etc. According to the trainers, it depends on the employer if he wants to pay for the additional cost of the visit. Furthermore, only $40 \%$ have information on the layout of the workplace and only $43 \%$ have information regarding ergonomic risk analysis for the specific tasks. However, in the additional remarks, it was stated by 10 trainers that the risk analysis should serve as a basis for discussing the work situation. Although $90 \%$ of the trainers consider it useful to organise courses on $\mathrm{MMH}$, most of them consider the current practice to be no more than an exercise in raising awareness.

\section{Implications for the future}

Legislation obliges employers to inform and instruct MMH workers on possible risks and on correct manual handling (Belgian Royal Decree of manual handling, 12/08/1993). Based on the results of the 
current study, the courses currently being run are in general too short to include all the content issues mentioned in the literature and thus cannot be effective. Therefore, the current courses should be considered only as an exercise in raising awareness and should be integrated in a global policy on $\mathrm{MMH}$. This multi-component global approach starts from a risk analysis that investigates work-related risk factors, at physical and organisational level. From this, recommendations should be given to adapt the workstation. Then, courses at different levels should be organised: raising awareness among employers and workers, specific MMH courses and courses oriented towards physical fitness, including promotion of general physical fitness and specific training for the trunk region. Recently, an expert meeting was organised by the Federal Public Service Employment, Labour and Social Dialogue, to discuss the current practice and to formulate further recommendations regarding organisation of $\mathrm{MMH}$ courses in companies.

\section{References}

[1] J. Bell, A. Burnett, Exercise for the primary, secondary and tertiary prevention of low back pain in the workplace: a systematic review. Journal of Occupational Rehabilitation, 19 (2009), 8-24.

[2] S. Bigos, J. Holland, C. Holland, J. Webster, M. Battie and J. Malmgren. High-quality controlled trials on preventing episodes of back problems: systematic literature review in working-age adults. The Spine Journal 9-2 (2009), 147-168.

[3] A. K. Blangsted, K. Sogaard, E.A. Hansen, H. Hannerz and G. Sjogaard. One-year randomized controlled trial with different physical-activity programs to reduce musculoskeletal symptoms in the neck and shoulders among office workers. Scand. J. Work. Environ. Health, 34-1 (2008), 55-65.

[4] R. Buchbinder, D. Jolley and M. Wyatt. Population based intervention to change back pain beliefs and disability: three part evaluation. BMJ 322-7301 (2001), 1516-1520.

[5] M. Burke, S. Sarpy, K. Smith-Crowe, S. Chan-Serafin, R. Salvador and G. Islam. Relative effectiveness of worker safety and health training methods. American Journal of Public Health 96-2 (2006), 315-324.

[6] A. Burton, F. Balagué, G. Cardon, H. Eriksen, Y. Henrotin, A. Lahad, A. Leclerc, G. Müller and van der Beek, A. European guidelines for the prevention in low back pain. European Spine Journal. 15-suppl 2 (2006), S136-168.

[7] A.K. Burton et al. Management of work-relevant upper limb disorders: a review, Occupational Medicine 59-1 (2009): 4452.

[8] E. Hall (2006). The perfect group size $=8-12$. Retrieved February $10^{\text {th }}$, via http://37signals.com/svn/archives2/edward hall the perfect $g$ roup_size_812.php

[9] Y. Hechoz, and A. Kai-Lik So. Exercise and non-specific low back pain: a literature review. Joint Bone Spine. 75-5 (2008), 533-539.

[10]A. Lahad, A.D. Malter, A.O. Berg and R.A. Deyo. The effectiveness of four interventions for the prevention of low back pain, JAMA 272-16 (1994):1286-1291.

[11]S. Linton and M. van Tulder, M. Preventive interventions for back and neck pain problems: what is the evidence? Spine. 267 (2001), 778-787.

[12]K. Martimo, J. Verbeek, J. Karppinen, A. Furlan, E. Takala, P. Kuijer, M. Jauhiainen and E. Viikari-Juntura. Effect of training and lifting equipment for preventing back pain in lifting and handling: systematic review. BMJ 336-7641 (2008), 429431.

[13]K. I. Proper, M. Koning, A.J. Van der Beek, V.H. Hildebrandt, R.J. Bosscher, W. van Mechelen, The Effectiveness of Worksite Physical Activity Programs on Physical Activity, Physical Fitness, and Health. Clinical Journal of Sport Medicine 13-2 (2003): 106-117.

[14] S. Rahman, J. Karpiinen, P. Leino-Arjas, S. Solovieva, E. Viikari-Juntura, The association between obesity and low back pain: a meta-analysis. American Journal of Epidemiology 171-2 (2009), 135-154.

[15]R. Shiri, J. Karpinen, P. Leino-Arjas, S. Solovieva and E. Viikari-Juntura, American Journal of Epidemiology 171-2 (2009): 135-154.

[16] T. Tveito, M. Hysing and H. Eriksen. Low back pain interventions at the workplace: a systematic literature review. Occupational Medicine, 54-1 (2004), 3-13. 